\title{
PERAMALAN BEBAN LISTRIK JANGKA MENENGAH DI WILAYAH TELUK KUANTAN DENGAN METODE FUZZY TIME SERIES CHENG
}

\author{
LANA FAUZIAH, DODI DEVIANTO, MAIYASTRI \\ Program Studi S1 Matematika, \\ Fakultas Matematika dan Ilmu Pengetahuan Alam, Universitas Andalas, \\ Kampus UNAND Limau Manis Padang, Indonesia. \\ email : lanafauziah20@gmail.com
}

Diterima 22 Juni 2019 Direvisi 6 Juli 2019 Dipublikasikan 4 Agustus 2019

\begin{abstract}
Abstrak. Kebutuhan terhadap energi listrik saat ini semakin meningkat karena sebagian besar aspek kehidupan manusia bergantung pada ketersediaan energi listrik. Akibatnya pihak penyalur listrik harus mempersiapkan kebutuhan energi listrik yang semakin meningkat tersebut. Pihak penyalur listrik harus memiliki perencanaan yang baik dan tepat dalam pendistribusian energi listrik. Salah satu upaya yang dapat dilakukan untuk membantu perencanaan tersebut adalah melakukan peramalan beban listrik untuk waktu yang akan datang. Metode fuzzy time series (FTS) Cheng merupakan salah satu metode yang dapat dilakukan untuk peramalan data time series yang menggunakan prinsip-prinsip fuzzy sebagai dasarnya. Pada penelitian ini dilakukan peramalan beban listrik jangka menengah di wilayah Taluk Kuantan dengan metode FTS Cheng untuk beberapa bulan ke depan. Hasil peramalan yang diperoleh tersebut dihitung tingkat akurasi peramalannya dengan menggunakan Mean Absolute Percentage Error (MAPE) sehingga diperoleh tingkat akurasi sebesar $4.45 \%$, yang artinya hasil peramalan beban listrik jangka menengah di wilayah Taluk Kuantan dengan metode FTS Cheng dikatakan sangat baik karena tingkat akurasi yang kurang dari $10 \%$.
\end{abstract}

Kata Kunci: Time Series, Beban Listrik, Fuzzy Time Series Cheng

\section{Pendahuluan}

Energi listrik saat ini telah menjadi salah satu bagian terpenting dalam kehidupan manusia. Apabila ketersediaan energi listrik tersebut tidak mencukupi kebutuhan manusia selaku konsumen, maka hal ini dapat mengganggu sebagian besar aspek kehidupan manusia, untuk itu pasokan energi listrik yang cukup merupakan hal yang sangat penting. Perusahan Listrik Negara (PLN) selaku penyalur utama energi listrik di Indonesia tentunya harus melakukan perencanaan yang tepat dalam mendistribusikan energi listrik tersebut agar total daya listrik yang dihasilkan dari sumber energi listrik dapat memenuhi seluruh kebutuhan konsumen. Oleh karena itu, perlu dilakukan peramalan beban listrik untuk waktu yang akan datang sebagai upaya untuk membantu pihak penyalur energi listrik dalam merancang perencanaan distribusi yang tepat. 
Pada tahun 1960-an seorang profesor bernama Lotfi A. Zadeh menemukan suatu teori yang dikenal dengan logika fuzzy. Kemudian pada tahun 2008 logika fuzzy tersebut dikembangkan oleh Cheng menjadi suatu metode peramalan data time series yang dikenal dengan nama metode fuzzy time series Cheng. Metode fuzzy time series merupakan metode peramalan data yang menggunakan prinsip-prinsip fuzzy sebagai dasarnya. Sistem peramalan dengan metode fuzzy time series menangkap pola dari data yang telah lalu kemudian digunakan untuk memproyeksikan data yang akan datang [4].

Pada tulisan ini akan dilakukan peramalan beban listrik jangka menengah di wilayah Taluk Kuantan dengan menggunakan metode fuzzy time series Cheng. Kemudian dari hasil peramalan yang diperoleh tersebut akan dihitung akurasi peramalannya menggunakan mean absolute percentage error (MAPE) untuk mengetahui seberapa akurat dan baik data hasil peramalan yang diperoleh dengan menggunakan metode tersebut.

\section{Metode Fuzzy Time Series Cheng}

\subsection{Peramalan}

Peramalan sering dilakukan untuk memprediksi dan membuat perencanaan dengan menggunakan data masa lalu dan data masa sekarang, agar dapat membuat prediksi di masa yang akan datang. Berdasarkan jangka waktunya, peramalan dapat dibagi menjadi tiga yaitu [3]:

(1) Peramalan Jangka Panjang (Long-Term Forecasting), yang memprediksikan keadaan dalam jangka waktu beberapa tahun ke depan (tahunan).

(2) Peramalan Jangka Menengah (Mid-Term Forecasting), yang memprediksikan keadaan dalam jangka waktu bulanan atau mingguan.

(3) Peramalan Jangka Pendek (Short-Term Forecasting), yang memprediksikan keadaan dalam jangka waktu harian hingga tiap jam.

\subsection{Fuzzy Time Series}

Perbedaan utama antara fuzzy time series dan conventional time series yaitu pada nilai yang digunakan dalam peramalan, yang merupakan himpunan fuzzy dari bilangan-bilangan real atas himpunan semesta yang ditentukan. Himpunan fuzzy dapat diartikan sebagai suatu kelas bilangan dengan batasan yang samar. Jika $U$ adalah himpunan semesta, $U=\left\{u_{1}, u_{2}, \cdots, u_{n}\right\}$, maka suatu himpunan fuzzy $A$ dari $U$ didefinisikan sebagai [1]:

$$
A_{i}=\frac{\mu_{A_{i}}\left(u_{1}\right)}{u_{1}}+\frac{\mu_{A_{i}}\left(u_{2}\right)}{u_{2}}+\cdots+\frac{\mu_{A_{i}}\left(u_{n}\right)}{u_{n}},
$$

dimana $\mu_{A_{i}}\left(u_{j}\right)$ adalah derajat keanggotaan $u_{j}$ dari himpunan fuzzy $A_{i}$ dengan $i, j=1,2, \cdots, n, n$ adalah banyak interval linguistik. Berikut adalah beberapa aturannya :

(1) Jika data observasi $\left(X_{t}\right)$ adalah $u_{1}$, maka derajat keanggotaan $u_{1}$ adalah 1. $u_{2}$ adalah 0,5 dan lainnya adalah 0 . 
(2) Jika data observasi $\left(X_{t}\right)$ adalah $u_{j} ; 1<j<n$, maka derajat keanggotaan $u_{j}$ adalah $1 . u_{j+1}$ dan $u_{j-1}$ adalah 0,5 dan lainnya adalah 0 .

(3) Jika data observasi $\left(X_{t}\right)$ adalah $u_{n}$, maka derajat keanggotaan $u_{n}$ adalah 1 . $u_{n-1}$ adalah 0,5 dan lainnya adalah 0 .

Definisi 2.1. [1] Misalkan $Y_{t} ;(t=\cdots, 0,1,2, \cdots)$, adalah himpunan bagian dari $R$, yang menjadi himpunan semesta dimana himpunan fuzzy $f_{i}(t) ;(i=1,2, \cdots)$ telah didefinisikan sebelumnya dan jadikan $F(t)$ menjadi kumpulan dari $f_{i}(t)$; $(i=1,2, \cdots)$. Maka $F(t)$ dinyatakan sebagai fuzzy time series terhadap $Y_{t} ;(t=$ $\cdots, 0,1,2, \cdots)$.

Definisi 2.2. [1] Misalkan $F(t)$ adalah fuzzy time series. Jika untuk sebarang waktu $t, F(t)=F(t-1)$ dan $F(t)$ hanya memiliki elemen yang terbatas maka $F(t)$ dikatakan sebagai time-invariant fuzzy time series. Demikian juga jika sebaliknya maka dikatakan time-variant fuzzy time series.

Definisi 2.3. [5] Andaikan $F(t)=A_{j}$ disebabkan oleh $F(t-1)=A_{i}$, maka Fuzzy Logical Relationship (FLR) didefinisikan sebagai $A_{i} \rightarrow A_{j}$.

Definisi 2.4. [5] Jika terdapat FLR yang diperoleh dari state $A_{2}$, maka transisi dibuat ke state yang lain $A_{i}, i=1,2, \cdots, n$, seperti $A_{2} \rightarrow A_{3}, A_{2} \rightarrow A_{2}, A_{2} \rightarrow A_{1}$. Oleh karena itu, FLR dikelompokkan menjadi Fuzzy Logical Relationship Group (FLRG) seperti berikut.

$$
A_{2} \rightarrow A_{1}, A_{2}, A_{3}
$$

\subsection{Fuzzy Time Series Cheng}

Tahapan-tahapan peramalan pada data time series menggunakan metode FTS Cheng adalah sebagai berikut [2]:

(1) Mendefinisikan himpunan semesta $U$ untuk kemudian dibagi menjadi beberapa interval dengan panjang yang sama. Setelah interval-interval tersebut terbentuk maka dilakukan terlebih dahulu perhitungan banyaknya data observasi yang dimuat oleh masing-masing interval. Jika terdapat jumlah data dalam suatu interval lebih banyak dari rata-rata data observasi pada tiap interval, maka interval tersebut dapat dibagi lagi menjadi dua interval yang lebih kecil.

(2) Mendefinisikan himpunan fuzzy untuk masing-masing interval linguistik.

(3) Melakukan proses fuzzifikasi pada data observasi. Proses fuzzifikasi adalah proses mengubah nilai numerik menjadi variabel fuzzy.

(4) Menentukan Fuzzy Logic Relations (FLR) dan Fuzzy Logic Relations Group (FLRG) dengan menggunakan Definisi 2.3 untuk FLR dan Definisi 2.4 untuk FLRG. Pada penentuan FLRG banyaknya kemunculan FLR yang sama tidak diabaikan.

(5) Menetapkan pembobotan pada FLR yang muncul. Misalkan sebagai berikut: $(t=1) A_{i} \rightarrow A_{i}$, diberikan bobot 1 .

$(t=2) A_{j} \rightarrow A_{i}$, diberikan bobot 1 .

$(t=3) A_{i} \rightarrow A_{i}$, diberikan bobot 2 . 
$(t=4) A_{i} \rightarrow A_{i}$, diberikan bobot 3 .

$(t=5) A_{i} \rightarrow A_{i}$, diberikan bobot 4 .

dengan $t$ menyatakan waktu.

(6) Membentuk matriks pembobotan dinormalisasi. Pembobotan yang diperoleh dinyatakan dalam bentuk matriks pembobotan yang telah dinormalisasi $\left(W_{n}(t)\right)$ yang persamaannya ditulis berikut:

$$
\begin{aligned}
W_{n}(t) & =\left[W_{1}^{\prime}, W_{2}^{\prime}, \cdots, W_{k}^{\prime}\right] \\
& =\left[\frac{W_{1}}{\sum_{h=1}^{k} W_{h}}, \frac{W_{2}}{\sum_{h=1}^{k} W_{h}}, \cdots, \frac{W_{k}}{\sum_{h=1}^{k} W_{h}}\right]
\end{aligned}
$$

(7) Menghitung nilai ramalan yang sesuai dengan persamaan berikut:

$$
F(t)=L_{d f}(t-1) \cdot W_{n}(t-1),
$$

dengan $L_{d f}(t-1)$ adalah matriks defuzzifikasi $L_{d f}=\left[m_{1}, m_{2}, \cdots, m_{k}\right]$ dimana $m_{k}$ adalah nilai tengah dari tiap-tiap interval dan $W_{n}(t-1)$ adalah matriks pembobotan yang telah dinormalisasi.

(8) Melakukan peramalan adaptif untuk memodifikasi hasil peramalan dengan persamaan berikut [4]:

$$
\text { Peramalan adaptif }(t)=X_{t-1}+h\left(F(t)-X_{t-1}\right),
$$

dengan $X_{t-1}$ adalah data aktual pada waktu $t-1, F(t)$ adalah data hasil peramalan pada waktu $t$, dan $h$ adalah parameter pembobotan yang nilainya berada antara 0.001 sampai 1 .

\subsection{Akurasi Peramalan}

Metode peramalan bertujuan untuk menghasilkan ramalan optimum yang tidak memiliki tingkat kesalahan besar. Beberapa metode yang dapat digunakan untuk mengukur tingkat akurasi adalah

(1) Mean Square Error (MSE) $=\frac{1}{n} \sum_{t=1}^{n}\left(X_{t}-\hat{X}_{t}\right)^{2}$.

(2) Mean Absolute Error (MAE) $=\frac{1}{n} \sum_{t=1}^{n}\left|X_{t}-\hat{X}_{t}\right|$.

(3) Mean Absolute Percentage Error (MAPE) $=\frac{100 \%}{n} \sum_{t=1}^{n}\left|\frac{X_{t}-\hat{X}_{t}}{X_{t}}\right|$,

dengan $X_{t}$ adalah data aktual pada waktu $t$ dan $\hat{X}_{t}$ adalah data hasil peramalan pada waktu $t$. Kriteria keakuratan MAPE yaitu jika $<10 \%$ maka ketepatan peramalan sangat baik, $10 \% \leq$ dan $<20 \%$ ketepatan peramalan baik, $20 \% \leq$ dan $\leq 50 \%$ ketepatan peramalan cukup, dan jika $>50 \%$ maka ketepatan peramalan tidak akurat.

\section{Peramalan dengan Metode Fuzzy Time Series Cheng}

Data yang digunakan adalah data pemakaian beban listrik di PT PLN Rayon Taluk Kuantan mulai dari bulan Mei 2012 sampai bulan Juni 2018. Kemudian dari data 
time series tersebut akan dilakukan peramalan beban litrik untuk 6 bulan ke depan, yaitu bulan Juli 2018 sampai Desember 2018. Tahap awal yang harus dilakukan adalah mendefinisikan himpunan semesta $U$ dan membaginya menjadi beberapa interval yang sama panjang. Berdasarkan data beban listrik tersebut diperoleh himpunan semesta $U$ yaitu $U=[7179000,13259000]$. Kemudian himpunan semesta $U$ tersebut dibagi menjadi beberapa interval seperti pada Tabel 1.

Tabel 1. Jumlah data observasi pada setiap interval linguistik

\begin{tabular}{|c|c|}
\hline Interval Linguistik & Jumlah Data Observasi \\
\hline$u_{1}=[7179000,7939000]$ & 2 \\
\hline$u_{2}=[7939000,8699000]$ & 5 \\
\hline$u_{3}=[8699000,9459000]$ & 9 \\
\hline$u_{4}=[9459000,10219000]$ & 7 \\
\hline$u_{5}=[10219000,10979000]$ & 7 \\
\hline$u_{6}=[10979000,11739000]$ & 15 \\
\hline$u_{7}=[11739000,12499000]$ & 15 \\
\hline$u_{8}=[12499000,13259000]$ & 14 \\
\hline
\end{tabular}

Karena jumlah data observasi pada interval $u_{6}, u_{7}$, dan $u_{8}$ melebihi rata-rata data observasi tiap interval maka interval tersebut dibagi menjadi 2 interval, seperti pada Tabel 2.

Tabel 2. Interval linguistik setelah proses pembagian

\begin{tabular}{|c|c|c|}
\hline Interval Linguistik & Nilai Tengah & Jumlah Data Observasi \\
\hline$u_{1}=[7179000,7939000]$ & $m_{1}=7559000$ & 2 \\
\hline$u_{2}=[7939000,8699000]$ & $m_{2}=8319000$ & 5 \\
\hline$u_{3}=[8699000,9459000]$ & $m_{3}=9079000$ & 9 \\
\hline$u_{4}=[9459000,10219000]$ & $m_{4}=9839000$ & 7 \\
\hline$u_{5}=[10219000,10979000]$ & $m_{5}=10599000$ & 7 \\
\hline$u_{6}=[10979000,11359000]$ & $m_{6}=11169000$ & 6 \\
\hline$u_{7}=[11359000,11739000]$ & $m_{7}=11549000$ & 9 \\
\hline$u_{8}=[11739000,12339000]$ & $m_{8}=12039000$ & 10 \\
\hline$u_{9}=[12339000,12499000]$ & $m_{9}=12419000$ & 5 \\
\hline$u_{10}=[12499000,12879000]$ & $m_{10}=12689000$ & 10 \\
\hline$u_{11}=[12879000,13259000]$ & $m_{11}=13069000$ & 4 \\
\hline
\end{tabular}

Tahap selanjutnya adalah mendefinisikan variabel linguistik kemudian melakukan proses fuzzifikasi pada data observasi, dapat dilihat pada Tabel 3.

$$
\begin{aligned}
& A_{1}=1 / u_{1}+0.5 / u_{2}+0 / u_{3}+0 / u_{4}+0 / u_{5}+0 / u_{6}+0 / u_{7}+\cdots+0 / u_{11} \\
& A_{2}=0.5 / u_{1}+1 / u_{2}+0.5 / u_{3}+0 / u_{4}+0 / u_{5}+0 / u_{6}+0 / u_{7}+\cdots+0 / u_{11} \\
& A_{3}=0 / u_{1}+0.5 / u_{2}+1 / u_{3}+0.5 / u_{4}+0 / u_{5}+0 / u_{6}+0 / u_{7}+\cdots+0 / u_{11} \\
& A_{4}=0 / u_{1}+0 / u_{2}+0.5 / u_{3}+1 / u_{4}+0.5 / u_{5}+0 / u_{6}+0 / u_{7}+\cdots+0 / u_{11} \\
& A_{5}=0 / u_{1}+0 / u_{2}+0 / u_{3}+0.5 / u_{4}+1 / u_{5}+0.5 / u_{6}+0 / u_{7}+\cdots+0 / u_{11}
\end{aligned}
$$




$$
\begin{aligned}
A_{6} & =0 / u_{1}+0 / u_{2}+0 / u_{3}+0 / u_{4}+0.5 / u_{5}+1 / u_{6}+0.5 / u_{7}+\cdots+0 / u_{11} \\
A_{7} & =0 / u_{1}+\cdots+0 / u_{5}+0.5 / u_{6}+1 / u_{7}+0.5 / u_{8}+0 / u_{9}+0 / u_{10}+0 / u_{11} \\
A_{8} & =0 / u_{1}+\cdots+0 / u_{5}+0 / u_{6}+0.5 / u_{7}+1 / u_{8}+0.5 / u_{9}+0 / u_{10}+0 / u_{11} \\
A_{9} & =0 / u_{1}+\cdots+0 / u_{5}+0 / u_{6}+0 / u_{7}+0.5 / u_{8}+1 / u_{9}+0.5 / u_{10}+0 / u_{11} \\
A_{10} & =0 / u_{1}+\cdots+0 / u_{5}+0 / u_{6}+0 / u_{7}+0 / u_{8}+0.5 / u_{9}+1 / u_{10}+0.5 / u_{11} \\
A_{11} & =0 / u_{1}+\cdots+0 / u_{5}+0 / u_{6}+0 / u_{7}+0 / u_{8}+0 / u_{9}+0.5 / u_{10}+1 / u_{11}
\end{aligned}
$$

Tabel 3. Proses fuzzifikasi

\begin{tabular}{|c|c|c|c|}
\hline No & Periode & Data Aktual & Fuzzifikasi \\
\hline 1 & Mei 2012 & 7586040 & $A_{1}$ \\
\hline 2 & Juni 2012 & 8345581 & $A_{2}$ \\
\hline 3 & Juli 2012 & 8676844 & $A_{2}$ \\
\hline$\vdots$ & $\vdots$ & $\vdots$ & $\vdots$ \\
\hline 72 & April 2018 & 12349002 & $A_{9}$ \\
\hline 73 & Mei 2018 & 13236238 & $A_{11}$ \\
\hline 74 & Juni 2018 & 12809942 & $A_{10}$ \\
\hline
\end{tabular}

Setelah dilakukan proses fuzzifikasi maka tahap selanjutnya yang dilakukan adalah menentukan fuzzy logic relations (FLR) dan fuzzy logic relations group (FLRG) sesuai definisi, dapat dilihat pada Tabel 4.

Tabel 4. Fuzzy Logic Relations Group (FLRG)

\begin{tabular}{|l|}
\hline \multicolumn{1}{|c|}{ FLRG } \\
\hline$A_{1} \rightarrow(2) A_{2}$ \\
\hline$A_{2} \rightarrow(1) A_{2},(4) A_{3}$ \\
\hline$A_{3} \rightarrow(1) A_{1},(2) A_{2},(2) A_{3},(3) A_{4},(1) A_{5}$ \\
\hline$A_{4} \rightarrow(3) A_{3},(3) A_{4},(1) A_{6}$ \\
\hline$A_{5} \rightarrow(1) A_{4},(2) A_{5},(2) A_{6},(2) A_{7}$ \\
\hline$A_{6} \rightarrow(2) A_{5},(1) A_{6},(1) A_{7},(2) A_{8}$ \\
\hline$A_{7} \rightarrow(1) A_{5},(1) A_{6},(2) A_{7},(2) A_{8},(2) A_{10},(1) A_{11}$ \\
\hline$A_{8} \rightarrow(1) A_{5},(3) A_{7},(4) A_{8},(1) A_{9},(1) A_{10}$ \\
\hline$A_{9} \rightarrow(1) A_{6},(1) A_{8},(2) A_{9},(1) A_{11}$ \\
\hline$A_{10} \rightarrow(1) A_{7},(1) A_{8},(1) A_{9},(6) A_{10},(2) A_{11}$ \\
\hline$A_{11} \rightarrow(1) A_{9},(3) A_{10}$ \\
\hline
\end{tabular}

Kemudian dari hasil FLR dan FLRG tersebut dibentuk menjadi suatu matriks pembobotan, dapat dilihat pada Tabel 5 .

Matriks pembobotan pada Tabel 5 kemudian dinormalisasi sehingga diperoleh matriks pada Tabel 6 .

Selanjutnya ditentukan matriks defuzzifikasi pada Tabel 7, yang komponennya 
Tabel 5. Matriks pembobotan

\begin{tabular}{|c|c|c|c|c|c|c|c|c|c|c|c|}
\hline$F(t-1)$ & \multicolumn{10}{|c|}{$F(t)$} \\
\cline { 2 - 13 } & $A_{1}$ & $A_{2}$ & $A_{3}$ & $A_{4}$ & $A_{5}$ & $A_{6}$ & $A_{7}$ & $A_{8}$ & $A_{9}$ & $A_{10}$ & $A_{11}$ \\
\hline$A_{1}$ & 0 & 2 & 0 & 0 & 0 & 0 & 0 & 0 & 0 & 0 & 0 \\
\hline$A_{2}$ & 0 & 1 & 4 & 0 & 0 & 0 & 0 & 0 & 0 & 0 & 0 \\
\hline$A_{3}$ & 1 & 2 & 2 & 3 & 1 & 0 & 0 & 0 & 0 & 0 & 0 \\
\hline$A_{4}$ & 0 & 0 & 3 & 3 & 0 & 1 & 0 & 0 & 0 & 0 & 0 \\
\hline$A_{5}$ & 0 & 0 & 0 & 1 & 2 & 2 & 2 & 0 & 0 & 0 & 0 \\
\hline$A_{6}$ & 0 & 0 & 0 & 0 & 2 & 1 & 1 & 2 & 0 & 0 & 0 \\
\hline$A_{7}$ & 0 & 0 & 0 & 0 & 1 & 1 & 2 & 2 & 0 & 2 & 1 \\
\hline$A_{8}$ & 0 & 0 & 0 & 0 & 1 & 0 & 3 & 4 & 1 & 1 & 0 \\
\hline$A_{9}$ & 0 & 0 & 0 & 0 & 0 & 1 & 0 & 1 & 0 & 2 & 1 \\
\hline$A_{10}$ & 0 & 0 & 0 & 0 & 0 & 0 & 1 & 1 & 1 & 4 & 2 \\
\hline$A_{11}$ & 0 & 0 & 0 & 0 & 0 & 0 & 0 & 0 & 1 & 3 & 0 \\
\hline
\end{tabular}

Tabel 6. Matriks pembobotan yang dinormalisasi

\begin{tabular}{|c|c|c|c|c|c|c|c|c|c|c|c|}
\hline$F(t-1)$ & \multicolumn{10}{|c|}{$F(t)$} \\
\cline { 2 - 12 } & $A_{1}$ & $A_{2}$ & $A_{3}$ & $A_{4}$ & $A_{5}$ & $A_{6}$ & $A_{7}$ & $A_{8}$ & $A_{9}$ & $A_{10}$ & $A_{11}$ \\
\hline$A_{1}$ & 0 & $2 / 2$ & 0 & 0 & 0 & 0 & 0 & 0 & 0 & 0 & 0 \\
\hline$A_{2}$ & 0 & $1 / 5$ & $4 / 5$ & 0 & 0 & 0 & 0 & 0 & 0 & 0 & 0 \\
\hline$A_{3}$ & $1 / 9$ & $2 / 9$ & $2 / 9$ & $3 / 9$ & $1 / 9$ & 0 & 0 & 0 & 0 & 0 & 0 \\
\hline$A_{4}$ & 0 & 0 & $3 / 7$ & $3 / 7$ & 0 & $1 / 7$ & 0 & 0 & 0 & 0 & 0 \\
\hline$A_{5}$ & 0 & 0 & 0 & $1 / 7$ & $2 / 7$ & $2 / 7$ & $2 / 7$ & 0 & 0 & 0 & 0 \\
\hline$A_{6}$ & 0 & 0 & 0 & 0 & $2 / 6$ & $1 / 6$ & $1 / 6$ & $2 / 6$ & 0 & 0 & 0 \\
\hline$A_{7}$ & 0 & 0 & 0 & 0 & $1 / 9$ & $1 / 9$ & $2 / 9$ & $2 / 9$ & 0 & $2 / 9$ & $1 / 9$ \\
\hline$A_{8}$ & 0 & 0 & 0 & 0 & $1 / 10$ & 0 & $3 / 10$ & $4 / 10$ & $1 / 10$ & $1 / 10$ & 0 \\
\hline$A_{9}$ & 0 & 0 & 0 & 0 & 0 & $1 / 5$ & 0 & $1 / 5$ & 0 & $2 / 5$ & $1 / 5$ \\
\hline$A_{10}$ & 0 & 0 & 0 & 0 & 0 & 0 & $1 / 9$ & $1 / 9$ & $1 / 9$ & $4 / 9$ & $2 / 9$ \\
\hline$A_{11}$ & 0 & 0 & 0 & 0 & 0 & 0 & 0 & 0 & $1 / 4$ & $3 / 4$ & 0 \\
\hline
\end{tabular}

merupakan nilai tengah dari interval linguistik yang mempunyai relasi dengan variabel linguistik pada $F(t-1)$.

Tabel 7. Matriks defuzzifikasi

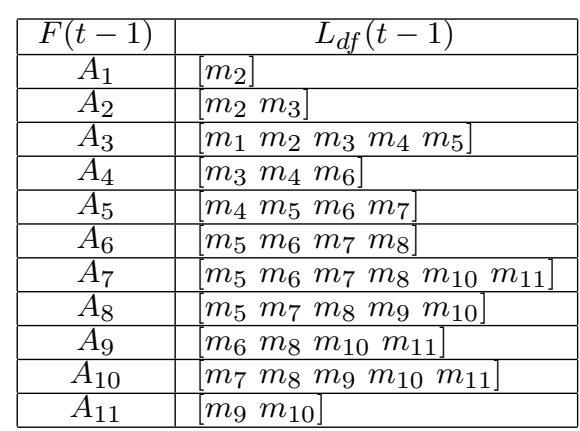


Kemudian untuk memperoleh hasil peramalan digunakan persamaan (2.4) dengan mengalikan matriks pada Tabel 6 dengan Tabel 7, sehingga diperoleh hasil peramalan beban listrik jangka menengah di wilayah Taluk Kuantan seperti pada Tabel 8 .

Tabel 8. Hasil peramalan beban listrik

\begin{tabular}{|c|c|c|c|}
\hline No & Periode & Data Aktual & Defuzzifikasi \\
\hline 1 & Mei 2012 & 7586040 & NA \\
\hline 2 & Juni 2012 & 8345581 & 8319000 \\
\hline 3 & Juli 2012 & 8676844 & 8927000 \\
\hline$\vdots$ & $\vdots$ & $\vdots$ & $\vdots$ \\
\hline \hline 75 & Juli 2018 & $*$ & 12544555.56 \\
\hline 76 & Agustus 2018 & $*$ & 12559000 \\
\hline 77 & September 2018 & $*$ & 12570818.18 \\
\hline 78 & Oktober 2018 & $*$ & 12580666.67 \\
\hline 79 & November 2018 & $*$ & 12589000 \\
\hline 80 & Desember 2018 & $*$ & 12596142.86 \\
\hline
\end{tabular}

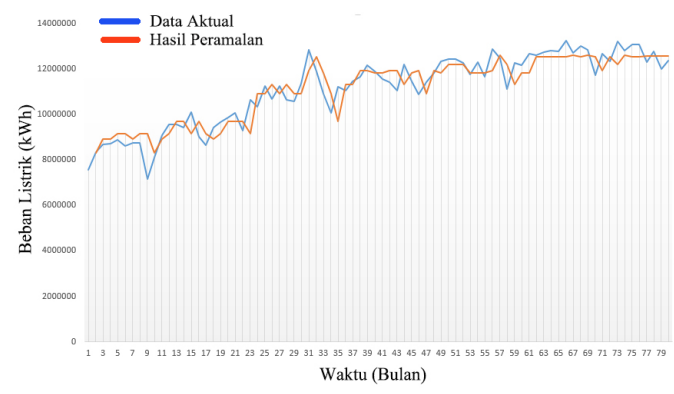

Gambar 1. Grafik data aktual dan hasil peramalan

Hasil peramalan di atas dapat pula dikatakan sebagai peramalan adaptif dengan mengambil parameter pembobotan $1(h=1)$. Kemudian dari hasil peramalan dan data observasi dihitung nilai akurasi peramalannya dengan hasil seperti pada Tabel 9.

Tabel 9. Akurasi peramalan

\begin{tabular}{|c|c|c|}
\hline MSE & MAE & MAPE \\
\hline 367280492972 & 481547.0678 & 4.446593656 \\
\hline
\end{tabular}

Kemudian dari nilai MAPE yang diperoleh, diselidiki kriteria keakuratannya, sehingga berdasarkan kriteria tersebut dikatakan bahwa hasil peramalan sangat 
baik, karena nilai MAPE yang diperoleh $<10 \%$.

\section{Kesimpulan}

Metode fuzzy time series Cheng dapat digunakan sebagai salah satu metode untuk meramalkan data beban listrik di wilayah Taluk Kuantan. Berdasarkan hasil peramalan tersebut diperoleh tingkat akurasi MSE sebesar 367280492972, MAE sebesar 481547.0678, dan MAPE sebesar $4.45 \%$ yang mana nilai MAPE tersebut kurang dari 10\% sehingga dapat disimpulkan bahwa peramalan beban listrik jangka menengah di wilayah Taluk Kuantan dengan menggunakan metode fuzzy time series Cheng menghasilkan nilai peramalan yang sangat baik.

\section{Daftar Pustaka}

[1] Chen, S. M. 1996. Forecasting enrollments based on fuzzy time series. Journal of Fuzzy Sets and System. 81(3) : 311 - 319

[2] Cheng, C. S., Chen, T. L., Teoh, H. J., dan Chiang, C. H. 2008. Fuzzy time-series based on adaptive expectation model for TAIEX forecasting. Expert Systems with Applications. 34 : $1126-1132$

[3] Montgomery, D. C., C.L. Jennings, dan M. Kulahci. 2008. Introduction to Time Series Analysis and Forecasting. Jhon Wiley \& Sons, Inc, New Jersey

[4] Tauryawati, M. L dan M.I. Irawan. 2014. Perbandingan metode fuzzy time series cheng dan metode box-jenkins untuk memprediksi IHSG. Jurnal Sains dan Seni POMITS. 3(2) : $34-39$

[5] Tsaur, R. 2012. A fuzzy time series-markov chain model with an application to forecast the exchange rate between the Taiwan and US dollar. International Journal of Innovative Computing, Information and Control. 8(7) : 4931 - 4942 